\title{
Lateral Load Capacity of Piles: A Comparative Study Between Indian Standards and Theoretical Approach
}

\author{
P. K. Jayasree ${ }^{1}$ (D) K. V. Arun ${ }^{2}$ R. Oormila ${ }^{1} \cdot$ H. Sreelakshmi ${ }^{1}$
}

Received: 6 November 2016/Accepted: 26 April 2018/Published online: 16 May 2018

(C) The Institution of Engineers (India) 2018

\begin{abstract}
As per Indian Standards, laterally loaded piles are usually analysed using the method adopted by IS 2911-2010 (Part 1/Section 2). But the practising engineers are of the opinion that the IS method is very conservative in design. This work aims at determining the extent to which the conventional IS design approach is conservative. This is done through a comparative study between IS approach and the theoretical model based on Vesic's equation. Bore $\log$ details for six different bridges were collected from the Kerala Public Works Department. Cast in situ fixed head piles embedded in three soil conditions both end bearing as well as friction piles were considered and analyzed separately. Piles were also modelled in STAAD.Pro software based on IS approach and the results were validated using Matlock and Reese (In Proceedings of fifth international conference on soil mechanics and foundation engineering, 1961) equation. The results were presented as the percentage variation in values of bending moment and deflection obtained by different methods. The results obtained from the mathematical model based on Vesic's equation and that obtained as per the IS approach were compared and the IS method was found to be uneconomical and conservative.
\end{abstract}

Keywords Lateral load · Piles ·

Modulus of subgrade reaction · IS 2911 (2010) .

Vesic's equation

P. K. Jayasree

jayasreepk@cet.ac.in

1 College of Engineering Trivandrum, Thiruvananthapuram, Kerala, India

2 Kerala Public Works Department, Thiruvananthapuram, Kerala, India

\section{Introduction}

Piles are always required to be designed to with stand the lateral loads in addition to the compression and tension loads. Lateral capacity of these piles depends on the properties of soil. Pile behaves as a transversely loaded beam in case of lateral loads and they transfer lateral load to surrounding soil by means of lateral resistance of the soil. Pile shifts horizontally in response to applied load which results in bending, rotation or translation of pile.

Based on fixity of pile head laterally loaded piles are classified as fixed head pile and free head pile according to whether the top portion of the pile is fixed or not. And based on the mode of functioning it is classified as friction piles and end bearing piles. Friction piles transfer the load through skin friction between the embedded surface of the pile and surrounding soil. And the end bearing piles transmit the loads through their bottom tips resting on a hard stratum.

Analysis conducted on laterally loaded piles in various software revealed that except STAAD.Pro all other methods overestimated the pile head deflection [1]. As piles under lateral loads are designed based on the maximum permissible deflection, the STAAD.Pro analysis can be effectively used to evaluate pile head deflections with some multiplication factor due to its consistently lower deflection values. The accuracy of results in STAAD.Pro will depend on the spring constant which in turn is related to modulus of subgrade reaction $\left(k_{\mathrm{s}}\right)$ of soil. Several equations have been developed to estimate $k_{\mathrm{s}}$ for elastic soils based on tests and theoretical analyses of which the methods for determination of $\mathrm{k}_{\mathrm{s}}$ value based on Vesic's [2] relation gave acceptable accuracy [3]. IS 2911-2010 (Part 1/Section 2) makes use of equivalent cantilever approach for the analysis of laterally loaded piles. Studies conducted using 
beams on elastic foundation approach was found to be efficient than IS approach [4].

Approach of conventionally used IS 2911 [5] in the design of lateral load carrying capacity of piles is conservative as stated by practising engineers of Public works department, Govt. of Kerala. Hence an attempt is made to study the behaviour of different types of laterally loaded piles resting on different soil media using the IS method and mathematical modelling based on Vesic's equation by using standard software package STAAD.Pro. By this it is expected to establish how much conservative is the IS method on comparison with the mathematical approach.

\section{Methodology}

Data including the structural drawings and bore log details of six pressed girder slab bridges were collected from the Kerala Public Works Department,. Thiruvananthapuram, Kerala. The bridge site locations chosen were Kurichikkal, Pullut bridge-1, Vakkayil, Pullut bridge-2, Ezhavapalam and Chengalayi. Three soil conditions namely medium sand, soft clay and stiff clay were selected randomly. The various loads acting on each bridge were calculated from geometric details as well as by using IRC-6 (2014) [6]. The loads taken into consideration were dead load (deck slab, hand rails, wearing coat, bearing, pedestal, abutment, dirt wall, wing wall, earth fill, and pile cap), live load, footpath live load, load due to breaking, earth pressure, temperature stress and shrinkage stress. From the total horizontal and vertical loads acting on pile group thus obtained, horizontal and vertical load acting on a single pile at each bridge site were determined and are tabulated in Table 1.

\section{IS 2911 (Part 1/Sec 2)-2010 Approach}

The behaviour of laterally loaded piles was analysed based on IS 2911 [5]. The IS approach always gives an approximate solution because of the complexity involved in many problems. The first step was to determine whether the pile behaved as a short rigid unit or as an infinitely long flexible member. This was done by calculating the stiffness factor,
$\mathrm{T}$ for a particular combination of pile and soil. Having calculated the stiffness factor, the criteria for behaviour as a short rigid pile or as a long elastic pile are related to the embedded length $\mathrm{L}$ of the pile. The depth from the ground surface to the point of virtual fixity was then calculated and used in the conventional elastic analysis for estimating lateral deflection and bending moment.

The lateral soil resistance for granular soils and normally consolidated clay which have varying soil modulus was analysed according to the modulus of subgrade reaction for which the recommended values are given in IS 2911 [5] as shown in Tables 2 and 3.

Using the modulus of subgrade reaction the stiffness factor $\mathrm{T}$ for granular soils and stiffness factor $\mathrm{R}$ for cohesive soils was found from Eqs. (1) and (2).

Stiffness factor in $\mathrm{m}, \quad T=\sqrt[5]{\frac{E I}{\eta_{h}}}$

Stiffness factor in $\mathrm{m}, \quad R=\sqrt[4]{\frac{E I}{K B}}$

where $\mathrm{E}$ is young's modulus of pile material in $\mathrm{MN} / \mathrm{m}^{2}$, I is the moment of inertia of the pile cross-section in $\mathrm{m}^{4}, \eta_{\mathrm{h}}$ is the modulus of subgrade reaction of granular soil in MN/ $\mathrm{m}^{3}$ and $\mathrm{B}$ is the width of pile shaft (diameter in case of circular piles) in $\mathrm{m}$

$K=\frac{0.3 k_{1}}{1.5 B}$

where $k_{1}$ is modulus of subgrade reaction in cohesive soils in $\mathrm{kN} / \mathrm{m}^{3}$.

The bending moment and deflection for fixed head piles are obtained from the Eqs. (4) and (5) respectively.

Fixed end moment, $\quad M_{F}=\frac{H\left(e+z_{f}\right)}{2}$

Deflection, $\quad y=\frac{H\left(e+z_{f}\right)^{3}}{12 E I} \times 10^{3}$

where $\mathrm{H}$ is the lateral load in $\mathrm{kN}$, $\mathrm{y}$ is the deflection of pile head in $\mathrm{mm}, \mathrm{E}$ is the Young's modulus of pile material in $\mathrm{kN} / \mathrm{m}^{2}, \mathrm{I}$ is the moment of Inertia of the pile cross-section

Table 1 Summary of load calculation for the six bridge site locations

\begin{tabular}{llll}
\hline Sl. No. & Site & Vertical load on single pile $(\mathrm{kN})$ & Horizontal load on single pile $(\mathrm{kN})$ \\
\hline 1 & Kurichikkal bridge & 1446.171 & 219.4603 \\
2 & Parallel bridge to Pullut 1 & 1384.322 & 233.6364 \\
3 & Vakkayil bridge & 1190.967 & 144.5068 \\
4 & Parallel bridge to Pullut 2 & 1299.424 & 191.0548 \\
5 & Ezhavapalam bridge & 1407.644 & 218.489 \\
6 & Chengalayi bridge & 1394.289 & 184.7431 \\
\hline
\end{tabular}


Table 2 Modulus of subgrade reaction for granular soils, $\eta_{\mathrm{h}}$ in $\mathrm{kN} / \mathrm{m}^{3}$ (Source: IS 2911(Part 1/Sec 2)-2010)

\begin{tabular}{lllll}
\hline S1. No. & Soil type & $\mathrm{N}($ blows $/ 30 \mathrm{~cm})$ & \multicolumn{2}{l}{ Range of $\eta_{\mathrm{h}}$ in $\mathrm{kN} / \mathrm{m}^{3} \times 10^{3}$} \\
\cline { 4 - 5 } & & Dry & $<0.2$ \\
2 & Very loose sand & $0-4$ & $<0.4$ & $0.2-1.4$ \\
3 & Loose sand & $4-10$ & $0.4-2.5$ & $1.4-5.0$ \\
4 & Medium sand & $10-35$ & $2.5-7.5$ & $5.0-12.0$ \\
\hline
\end{tabular}

The $\eta_{\mathrm{h}}$ values may be interpolated for intermediate for intermediate standard penetration values, $\mathrm{N}$

Table 3 Modulus of subgrade reaction in cohesive soils, $\mathrm{k}_{1}$ in $\mathrm{kN} / \mathrm{m}^{3}$. (Source: IS 2911(Part 1/Sec 2)-2010)

\begin{tabular}{llll}
\hline Sl. No. & Soil consistency & Unconfined compression strength, $\mathrm{q}_{\mathrm{u}}\left(\mathrm{kN} / \mathrm{m}^{2}\right)$ & Range of $\mathrm{k}_{1} \mathrm{kN} / \mathrm{m}^{3} \times 10^{3}$ \\
\hline 1 & Soft & $25-50$ & $4.5-9.0$ \\
2 & Medium stiff & $50-100$ & $9.0-18.0$ \\
3 & Stiff & $100-200$ & $18.0-36.0$ \\
4 & Very stiff & $200-400$ & $36.0-72.0$ \\
5 & Hard & $>400$ & $>72.0$ \\
\hline
\end{tabular}

For $\mathrm{q}_{\mathrm{u}}<25, \mathrm{k}_{1}$ may be taken as zero, which implies that there is no lateral resistance

in $\mathrm{m}^{4}, \mathrm{z}_{\mathrm{f}}$ is depth to point of fixity in $\mathrm{m}$ and $\mathrm{e}$ is the cantilever length above ground/bed to the point of load application in $\mathrm{m}$.

The depth to point of fixity and cantilever length above ground/bed to the point of load application was obtained from the corresponding in IS 2911 [5]. The values of subgrade reactions obtained for each bridge site location are shown in Table 4.

\section{Mathematical Model based on Vesic's Equation}

The behaviour of laterally loaded piles was analysed using the mathematical model based on Vesic's equation. Vesic [2] analysed an infinite horizontal beam on elastic foundation and comparing the results with those obtained by the use of subgrade reaction theory related the modulus of subgrade reaction to the elastic parameters. The modulus of subgrade reaction of different soil layers in each bridge site was calculated using Vesic's equation as given in Eq. (6).
$k_{s}=\frac{E_{s}}{B\left(1-\mu_{s}^{2}\right)}$

where $\mathrm{k}_{\mathrm{s}}$ is the modulus of subgrade reaction in $\mathrm{kN} / \mathrm{m}^{3}, \mathrm{E}_{\mathrm{S}}$ is the modulus of elasticity of soil in $\mathrm{kN} / \mathrm{m}^{2}$, B is the width of pile in $\mathrm{m}$ and $\mu_{\mathrm{s}}$ is the Poisson's ratio [7]. The modulus of elasticity of soil was found using Eq. (7) for cohesive soils and Eq. (8) for granular soils [7].

$$
\begin{aligned}
& \mathrm{E}_{\mathrm{s}}=600 \mathrm{c}_{\mathrm{u}} \quad\left(\mathrm{kN} / \mathrm{m}^{2}\right) \\
& \mathrm{E}_{\mathrm{s}}=750+80 \mathrm{~N} \quad\left(\text { tonnes } / \mathrm{m}^{2}\right)
\end{aligned}
$$

where $c_{u}=6 \mathrm{~N}$ [8], $\mathrm{N}$ is the SPT value of soil and $c_{\mathrm{u}}$ is the undrained shear strength of soil in $\mathrm{kN} / \mathrm{m}^{2}$.

\section{Numerical Modelling}

The pile was modelled as a beam element in STAAD.Pro software. The soil springs were used to idealize the soil support for pile in the horizontal direction at number of nodes along pile length. The spring constants were

Table 4 Values of modulus of subgrade reaction

\begin{tabular}{lllll}
\hline S1. No. & Bridge site & Type of pile & Soil type & Modulus of subgrade reaction $\mathrm{Ks}\left(\times 1000 \mathrm{kN} / \mathrm{m}^{3}\right)$ \\
\hline 1 & Kurichikkal bridge & Friction pile & Medium sand & 3.2 \\
2 & Parallel bridge to Pullut 1 & End bearing pile & Medium sand & 3.2 \\
3 & Vakkayil bridge & Friction pile & Soft clay & 6.75 \\
4 & Parallel bridge to Pullut 2 & End bearing pile & Soft clay & 6.75 \\
5 & Ezhavapalam bridge & Friction pile & Medium clay & 13.5 \\
6 & Chengayil bridge & End bearing pile & Medium clay & 13.5 \\
\hline
\end{tabular}


Table 5 Material properties assigned to the piles in STAAD.Pro

\begin{tabular}{lll}
\hline Geometry & Beam element \\
\hline Properties & Modulus of elasticity, E $(\mathrm{kPa})$ & 31622.78 \\
& Poisson's ratio, $\mu$ & 0.17 \\
& Thermal coefficient, $\alpha\left(/{ }^{\circ} \mathrm{C}\right)$ & $10^{-5}$ \\
& Density, $\rho\left(\mathrm{kN} / \mathrm{m}^{3}\right)$ & 24 \\
& Shear modulus, $\mathrm{G}\left(\mathrm{kN} / \mathrm{m}^{2}\right)$ & 13514.0 \\
& Support condition & Fixed at top \\
& & Pinned at bottom \\
\hline
\end{tabular}

estimated using modulus of subgrade reaction $\mathrm{k}_{\mathrm{s}}$ given in Eq. (6).

Pre-processing was done in order to assign the material properties for spring based on bore log details. Initially the pile geometry was created as per the drawing. Material properties of M40 concrete were then assigned to these piles. Next step was to create the support conditions at both the end nodes. The entire length of pile was divided by adding nodes at regular intervals. The spring supports were created corresponding to the various types of soil along the pile length using Eq. (5) and then it was assigned at nodes for their respective depth. The material properties assigned to the piles are given in Table 5 .

The piles were loaded at the fixed end by applying a horizontal load and a vertical load as obtained in Table 1 . The analysis of the model was then carried out. Bending moment and displacement values were obtained from analysis. The maximum bending moment was obtained at the fixed end from the bending moment diagram. Figure 1 shows the soil spring model for Kurichikkal Bridge based on IS approach. The maximum value of bending moment at nodes along with the bending moment diagram is shown in Fig. 2.

\section{Validation of the Numerical Model}

The $\mathrm{k}_{\mathrm{s}}$ selected from IS 2911-2010 for the major soil condition was used for modelling soil springs in STAAD.Pro. In this approach $\mathrm{K}_{\mathrm{s}}$ as obtained from Table 4 was assigned for all supporting springs as spring stiffness and analysed to obtain bending moment and deflection of the piles.

The results thus obtained from STAAD.Pro were validated by comparing with the result obtained from Matlock and Reese [9] equation. The Matlock and Reese [9] equation for bending moment and deflection of laterally loaded piles are given in Eqs. (9) and (10) (Fig. 3).

Bending moment, $\quad M_{Z}=C_{m} \times H T$
Deflection, $\quad \rho=C_{Y} \times \frac{H T^{3}}{E_{P} I_{P}}$

where $\mathrm{C}_{\mathrm{m}}$ is the moment coefficient, $\mathrm{C}_{\mathrm{Y}}$ is the deflection coefficient, $\mathrm{H}$ is the lateral load in $\mathrm{kN}$, $\mathrm{T}$ is the stiffness factor in $\mathrm{m}, \mathrm{E}_{\mathrm{P}}$ is the Young's modulus of pile material in $\mathrm{kN} / \mathrm{m}^{2}, I_{P}$ is the moment of inertia of the pile cross-section in $\mathrm{m}^{4}$ and $\eta_{\mathrm{h}}$ is the modulus of subgrade reaction in $\mathrm{MN} /$ $\mathrm{m}^{3}$. The value of bending moment coefficient and deflection coefficient were obtained from IS 2911 [5].

The results obtained by using the Matlock and Reese [9] equation and that obtained by using STAAD.Pro were compared together and are tabulated in Table 6.

Based on the comparison between values obtained for bending moment and deflection by using Reese and Matlock solution [9] and STAAD.Pro gave an acceptable percentage of variation. For bending moment as well as the deflection, the percentage variation obtained was only below which is quite acceptable and hence the values obtained using STAAD.Pro was validated.

\section{Results and Discussions}

The deflections and bending moments calculated based on IS 2911 are tabulated in Table 7.

The values obtained for bending moment and deflection as specified in IS 2911(part 1/sec 2)-2010 and using the Standard software package STAAD.Pro with the value of modulus of subgrade reaction $\mathrm{K}_{\mathrm{s}}$ calculated as per the IS 2911(part 1/sec 2)-2010 was compared and tabulated in Table 8.

On the analysis of the results obtained it was evident that the percentage variation in bending moment and deflection by the two methods was showing a wide range based on the soil conditions and irrespective of whether a friction pile or end bearing pile. For cohesion less soil condition in the case of both friction pile and end bearing pile the percentage variation of bending moment was about $38 \%$ and that of deflection was about $39 \%$. The variation obtained was slight higher in the case of cohesive soil conditions. For cohesive soil condition in the case of both friction pile and end bearing pile the percentage variation of bending moment was about $60 \%$ and that of deflection was about $84 \%$.

The values obtained for bending moment and deflection as specified in IS 2911(part 1/sec 2)-2010 and using the Standard software package STAAD.Pro with the value of modulus of subgrade reaction $\mathrm{K}_{\mathrm{s}}$ calculated as per Vesic's equation is compared and is tabulated in Table 9.

On comparing the results of bending moment and deflection from IS 2911-2010 and STAAD.Pro with $\mathrm{K}_{\mathrm{s}}$ based on Vesic's equation it can be inferenced that for 


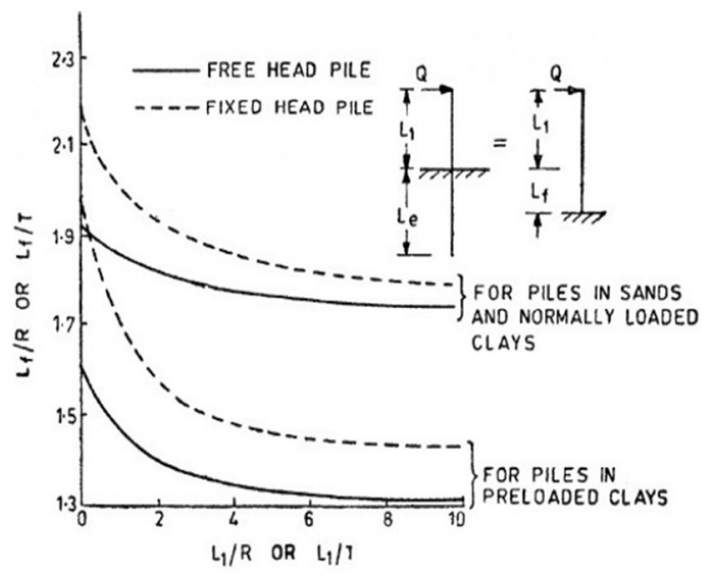

WHERE, $L_{1}=e$ and $L_{f}=2 f$

Fig. 1 Graph showing depth of fixity where, $\mathrm{L}_{1}=3 \mathrm{x}$ diameter of piles. Source: IS 2911(Part 1/Sec 2)-2010

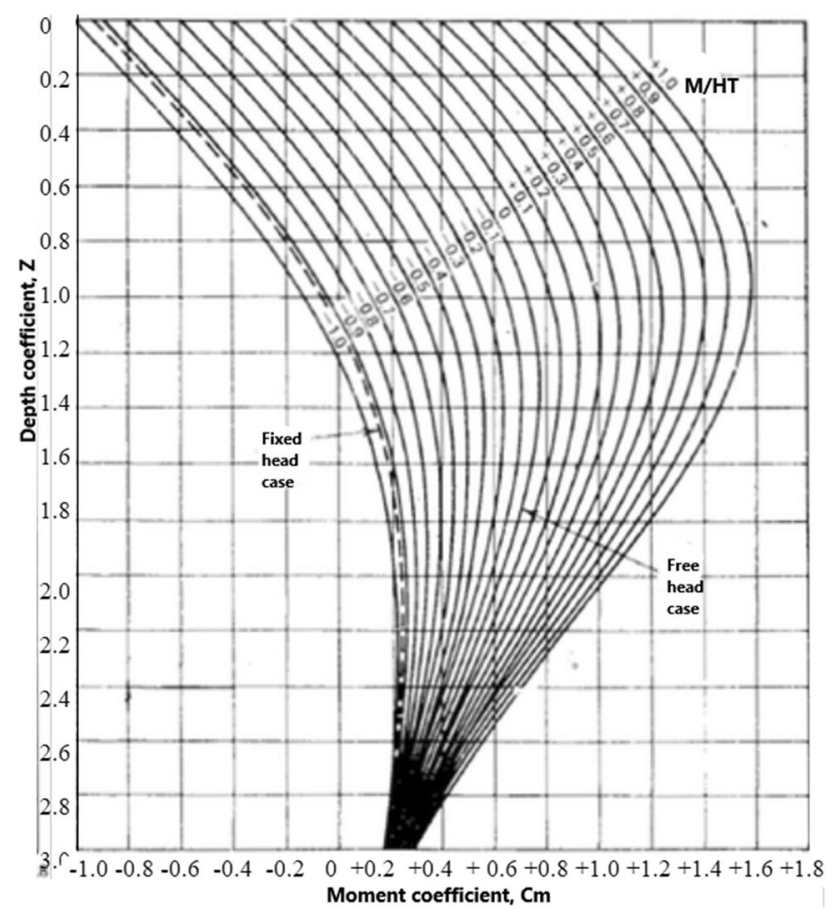

Fig. 2 Graph showing the values of bending moment coefficient. Source: Matlock and Reese [9]

cohesionless soil condition the percentage variation in bending moment is about $66 \%$ and that of deflection is about $90 \%$. This does not make a relevant variation in the case of whether friction pile or endbearing pile. But the case is different for cohesive soil condition. The friction piles in cohesive soil condition show about $75 \%$ variation in bending moment and that of deflection as about $95 \%$. Whereas the endbearing piles in the same soil condition show only about $50 \%$ variation in bending moment and that of deflection as about $75 \%$.

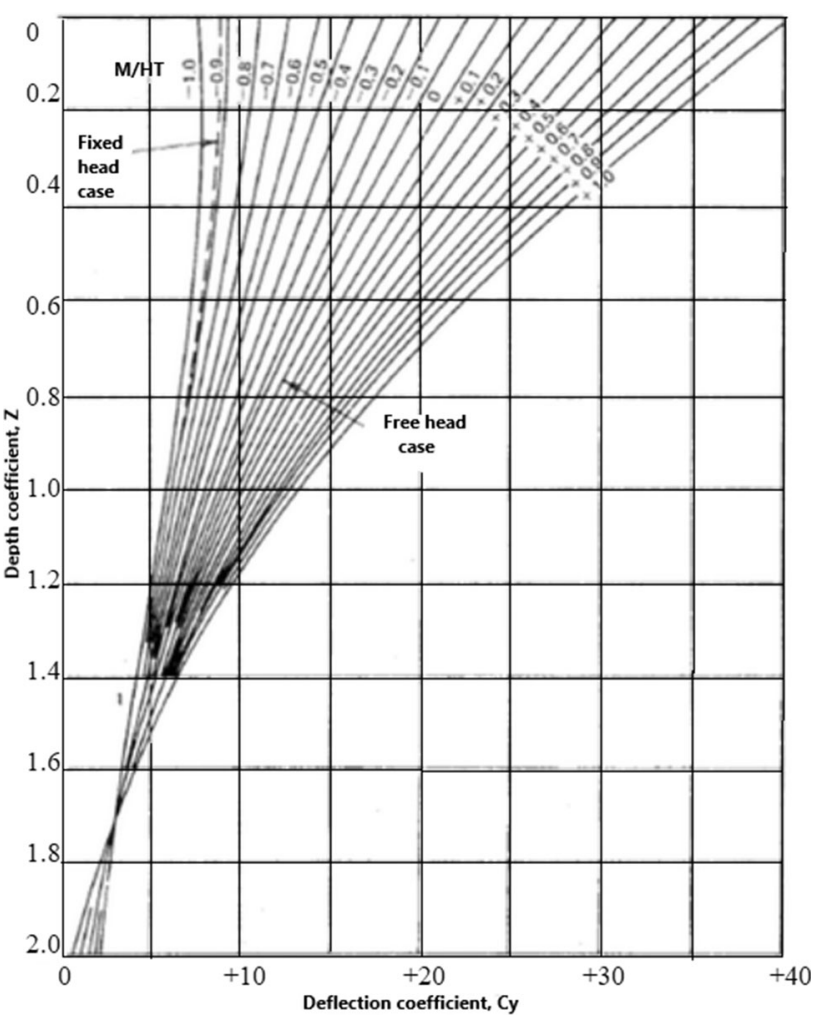

Fig. 3 Graph showing the values of deflection coefficient. Source: Matlock and Reese [9]

In both analyses that is while analyzing the comparison between the values obtained for bending moment and deflection as specified in IS 2911 [5] and using the Standard software package STAAD. Pro with the value of modulus of subgrade reaction $\mathrm{K}_{\mathrm{s}}$ calculated as per the IS 2911(part 1/sec 2)-2010 itself and with the value of modulus of subgrade reaction $\mathrm{K}_{\mathrm{s}}$ calculated as per Vesic's [2] equation the values of bending moment and deflection was found to be very much higher when it is calculated as specified in the conventional IS 2911 [5].

\section{Conclusion}

An attempt was made to quantify the extent to which the IS method is conservative for the design of laterally loaded piles. The bending moment and deflection obtained by using the conventional IS 2911 [5] method was found to be $80 \%$ higher than that obtained as per the mathematical spring model in STAAD.Pro based on Vesic's equation. Since the Kerala Public Works Department is currently adopting the conventional IS 2911 [5] method for the design of laterally loaded piles in bridges, they are considering higher value of bending moment as well as deflection than that obtained from the mathematical model based on Vesic's equation. The designs done using this IS 
Table 6 Bending moment and Deflection results of Reese and Matlock solution [9] and STAAD.Pro with Ks based on IS 2911-2010

\begin{tabular}{|c|c|c|c|c|c|c|}
\hline \multirow[t]{2}{*}{ Site } & \multicolumn{3}{|l|}{$\mathrm{BM}(\mathrm{kN} \mathrm{m})$} & \multicolumn{3}{|l|}{ Deflection (mm) } \\
\hline & $\begin{array}{l}\text { Reese and Matlock } \\
\text { solution (1961) }\end{array}$ & STAAD.Pro & $\begin{array}{l}\text { Percentage } \\
\text { variation }(\%)\end{array}$ & $\begin{array}{l}\text { Reese and Matlock } \\
\text { solution (1961) }\end{array}$ & STAAD.Pro & $\begin{array}{l}\text { Percentage } \\
\text { variation }(\%)\end{array}$ \\
\hline Kurichikkal & 813.53 & 736.391 & 9.70 & 3.89 & 4.494 & 13.44 \\
\hline $\begin{array}{l}\text { Parallel bridge to } \\
\text { Pullut-1 }\end{array}$ & 866.09 & 794.342 & 8.28 & 4.137 & 4.942 & 16.29 \\
\hline
\end{tabular}

Table 7 Deflections and bending moments based on IS 2911

\begin{tabular}{|c|c|c|c|c|c|c|c|}
\hline S1. No. & Site & $\mathrm{K}_{\mathrm{s}}\left(\times 1000 \mathrm{kN} / \mathrm{m}^{3}\right)$ & Stiffness factor ( $\mathrm{T}$ or $\mathrm{R})$ & Diameter (m) & $\mathrm{z}_{\mathrm{f}}(\mathrm{m})$ & $\begin{array}{l}\text { Deflection } \\
(\mathrm{mm})\end{array}$ & Bending moment $(\mathrm{kN} \mathrm{m})$ \\
\hline 1 & Kurichikkal bridge & 3.20 & 3.99 & 1.20 & 7.37 & 8 & 1204 \\
\hline 2 & Pullut bridge-1 & 3.20 & 3.99 & 1.20 & 7.37 & 8 & 1282 \\
\hline 3 & Vakkayil bridge & 6.75 & 6.99 & 1.20 & 10.62 & 11 & 1028 \\
\hline 4 & Pullut bridge- 2 & 6.75 & 6.99 & 1.20 & 10.62 & 14 & 1359 \\
\hline 5 & $\begin{array}{l}\text { Ezhavapalam } \\
\text { bridge }\end{array}$ & 13.50 & 5.88 & 1.20 & 8.46 & 10 & 1318 \\
\hline 6 & Chengalayi bridge & 13.50 & 5.88 & 1.20 & 8.81 & 9 & 1147 \\
\hline
\end{tabular}

Table 8 Results of bending moment and deflection from IS 2911-2010 and STAAD.Pro with Ks based on IS 2911-2010

\begin{tabular}{|c|c|c|c|c|c|c|c|}
\hline \multirow{2}{*}{$\begin{array}{l}\text { Sl. } \\
\text { No. }\end{array}$} & \multirow[t]{2}{*}{ Site } & \multicolumn{2}{|l|}{ IS $2911-2010$} & \multicolumn{2}{|l|}{ STAAD.Pro } & \multirow{2}{*}{$\begin{array}{l}\text { Percentage variation in } \\
\text { bending moment }(\%)\end{array}$} & \multirow{2}{*}{$\begin{array}{l}\text { Percentage variation in } \\
\text { deflection }(\%)\end{array}$} \\
\hline & & $\begin{array}{l}\text { Bending moment } \\
(\mathrm{kN} \mathrm{m})\end{array}$ & $\begin{array}{l}\text { Deflection } \\
(\mathrm{m})\end{array}$ & $\begin{array}{l}\text { Bending moment } \\
(\mathrm{kN} \mathrm{m})\end{array}$ & $\begin{array}{l}\text { Deflection } \\
(\mathrm{m})\end{array}$ & & \\
\hline 1 & $\begin{array}{l}\text { Kurichikkal } \\
\text { bridge }\end{array}$ & 1204.125 & 7.507 & 736.391 & 4.494 & 38.84 & 40.13 \\
\hline 2 & $\begin{array}{l}\text { Pullut bridge- } \\
\quad 1\end{array}$ & 1281.906 & 7.992 & 794.342 & 4.942 & 38.03 & 38.16 \\
\hline 3 & $\begin{array}{r}\text { Vakkayil } \\
\text { Bridge }\end{array}$ & 1027.534 & 10.759 & 409.634 & 1.742 & 60.13 & 83.81 \\
\hline 4 & $\begin{array}{l}\text { Pullut bridge- } \\
\quad 2\end{array}$ & 1358.519 & 14.225 & 541.56 & 2.303 & 60.14 & 83.81 \\
\hline 5 & $\begin{array}{l}\text { Ezhavapalam } \\
\text { bridge }\end{array}$ & 1317.632 & 9.924 & 534.304 & 1.644 & 59.45 & 83.43 \\
\hline 6 & $\begin{array}{l}\text { Chengalayi } \\
\text { bridge }\end{array}$ & 1146.687 & 9.149 & 447.944 & 1.36 & 60.93 & 85.13 \\
\hline
\end{tabular}

Table 9 Results of bending moment and deflection from IS 2911-2010 and STAAD.Pro with Ks based on Vesic's equation

\begin{tabular}{|c|c|c|c|c|c|c|c|}
\hline \multirow{2}{*}{$\begin{array}{l}\text { Sl. } \\
\text { No. }\end{array}$} & \multirow[t]{2}{*}{ Site } & \multicolumn{2}{|l|}{ IS $2911-2010$} & \multicolumn{2}{|l|}{ STAAD.Pro } & \multirow{2}{*}{$\begin{array}{l}\text { Percentage variation in } \\
\text { Bending moment }(\%)\end{array}$} & \multirow{2}{*}{$\begin{array}{l}\text { Percentage variation in } \\
\text { deflection }(\%)\end{array}$} \\
\hline & & $\begin{array}{l}\text { Bending moment } \\
(\mathrm{kN} \mathrm{m})\end{array}$ & $\begin{array}{l}\text { Deflection } \\
\text { (m) }\end{array}$ & $\begin{array}{l}\text { Bending moment } \\
(\mathrm{kN} \mathrm{m})\end{array}$ & $\begin{array}{l}\text { Deflection } \\
\text { (m) }\end{array}$ & & \\
\hline 1 & Kurichikkal & 1204.125 & 7.507 & 417.202 & 0.745 & 65.35 & 90.07 \\
\hline 2 & $\begin{array}{l}\text { Pullut } \\
\quad \text { bridge-1 }\end{array}$ & 1281.906 & 7.992 & 397.663 & 0.618 & 68.97 & 92.27 \\
\hline 3 & Vakkayil & 1027.534 & 10.759 & 254.721 & 0.469 & 75.21 & 95.64 \\
\hline 4 & $\begin{array}{l}\text { Pullut } \\
\quad \text { bridge-2 }\end{array}$ & 1358.519 & 14.225 & 545.749 & 2.327 & 59.83 & 83.64 \\
\hline 5 & Ezhavapalam & 1317.632 & 9.924 & 325.463 & 0.334 & 75.29 & 96.63 \\
\hline 6 & Chengalayi & 1146.687 & 9.149 & 635.255 & 2.619 & 44.6 & 71.36 \\
\hline
\end{tabular}


2911 [5] is hence proven to be uneconomical and conservative.

Acknowledgements The authors are thankful to the Engineers in Kerala Public Works Department for their help and support in data collection.

\section{References}

1. K.C. Birid, Pile head deflection analysis based on theory, software and field tests, in Proceedings of Indian Geotechnical Conference, Pune (2015), pp. 17-19

2. A.S. Vesic, Bending of beam resting on isotropic elastic solids. J. Eng. Mech. Div. ASCE 87(2), 35-53 (1961)

3. J. Sadrekarimi, M. Akbarzad, Comparative study of methods of determination of coefficient of subgrade reaction. Electron. J. Geotech. Eng. 14(Bundle E), 1-14 (2009)
4. J.C. Shukla, P.J. Shukla, D.L. Shah, Comparison of lateral load capacity of pile using simplified linear spring approach and IS 2911(2010), in Proceedings of Indian Geotechnical Conference, Roorkee (2013), pp. 22-24

5. IS 2911(Part I/Sec II):2010, Design and Construction of Pile Foundations (Bureau of Indian Standards, New Delhi)

6. IRC 6 :2014, Standard Specifications and Code of Practice for Road Bridges, Section II-Loads and Stresses (Indian Roads Congress, New Delhi)

7. J.E. Bowles, Foundation Analysis and Design, 5th edn (The McGraw-Hill Companies, Inc., New York., 1997), pp. 123, 308, 502-503

8. J.E. Bowles, Foundation Analysis and Design, 4th edn. (The McGraw-Hill Companies, Inc., New York, 1988), p. 308

9. H. Matlock, L.C. Reeses, Foundation analysis of offshore pile supported structures, in Proceedings of fifth international conference on soil mechanics and foundation engineering, France, vol. 2 (1961), pp. 91-97 